\title{
Biodiversity of noctuid moths (Lepidoptera: Noctuidae) in the agroecosystems of Mashhad County
}

\begin{abstract}
Lepidoptera with more than 150,000 species is the second largest and the most diverse order in the class Insecta. Members of this order compromise advantages in biodiversity studies because they have high diversity, relatively easy to identify, especially the butterflies and larger moths. Present study explored the Noctuid fauna of Mashhad County and estimated the biodiversity indices in agroecosystem. Data collecting were made randomly in the totally 31 sampling localities, for 3 days in each week, by using automated light traps. A total of 657 specimens of noctuid moths representing 38 different species were collected which belonging to eight subfamilies including Plusiinae, Metoponiinae, Acontiinae, Heliothinae, Bryophilinae, Xyleninae, Hadeninae and Noctuinae. More than $50 \%$ of the Noctuidae in the agroecosytems of Mashhad County belonging to three subfamilies Plusiinae, Heliothinae and Noctuinae. The overall insect biodiversity index of ShanonWiener was 3.11 and evenness was 0.85 . The highest level of noctuids population, among the five collecting months, is recorded in the June 2014 and the lowest is in the April 2014. Overall biodiversity indices showed relatively high biodiversity of Noctuidae in the study area, but existence of dominant species. Moreover, results showed that family Noctuidae was to some extent evenly distributed in the study area $(0.85)$ with the dominance of some species such as Spodoptera exigua (Hübner, 1808) and Heliocoverpaarmigera (Hübner, 1808)
\end{abstract}

Keywords: agriculture, fauna, mashhad moths, species diversity
Volume 2 Issue 2 - 2018

\author{
Mohammad Mahdi Rabieh \\ Department of Plant Protection, University of Birjand, Iran
}

Correspondence: Mohammad Mahdi Rabieh, Department of Plant Protection, Faculty of Agriculture, University of Birjand, Birjand, Iran, Email mmrabie@birjand.ac.ir

Received: January 06, 2018 | Published: April 09, 2018

\section{Introduction}

Biodiversity is a contraction of the term biological diversity that refers to the variety within the living world. The number of different species that are represented in a given community (whether wild or domesticated) within a geographical area is referred as species diversity. It includes two components: species richness which is a simple count of species, and species evenness which quantifies how equal the abundances of the species are. ${ }^{1}$ Species richness provides an extremely useful measure of diversity when a complete catalogue of species in the community is achieved. ${ }^{2}$

Slightly over one million species of insects have been described, that is, more than half of the world's known animal species in which Lepidoptera with more than 150,000 species is the second largest and the most diverse order in the class Insecta. ${ }^{3}$ The activities of Lepidopteran larvae are almost entirely the reason of economic importance of this order in the Agroecosystems. They have chewingtype mouthparts and a polyphagous diet which place them among the world's greatest pests with a worldwide distribution. ${ }^{4}$ Lepidoptera compromise advantages in biodiversity studies because they have high diversity, relatively easy to identify, especially the butterflies and larger moths, and amenable to quantitative sampling. They are found in many habitats and niches, making ecological comparisons possible, and they can indicate areas of endemism. ${ }^{5}$ Because of the inadequate collectings in many areas, only a fraction of the worlds biodiversity is currently preserved in collections and this with the lack of a central database containing images of the known lepidopteran type specimens, create needs for enhancing lepidopteran biodiversity studies. $^{4}$
The moths of the family Noctuidae include the largest family of Lepidoptera. Estimates of the number of known species vary considerably but the most frequently quoted is more than 25,000 described species. ${ }^{6}$ Not only are the noctuids a large family numerically, but they also comprise extremely economically important species. ${ }^{7}$ The larvae of many genera (e.g. Spodoptera, Heliothis, Euxoa, Earias and Trichoplusia) are well known as army-worms, cutworms, bollworms and stem-borers and cause a large quantity of crop loss each year in the world. A complete biodiversity information can thus be seen to be an essential prerequisite to the efficient use of the resources available to combat these pest species. The Noctuidae have a worldwide distribution, with the greatest diversity in the Neotropics where about a third of the world's fauna is found. ${ }^{4}$ Study on the family Noctuidae of Iran is started at 1858 by Bienert ${ }^{8}$ in his expedition to the northern mountains of the country ${ }^{8}$ and continued by several foreign researchers. Recently exploration of the Iranian noctuid fauna in several projects conducted by Iranian researchers along with foreign lepidopterologists' have resulted in the description of many new species and raises the recorded species as about 1180 species. ${ }^{5,9-14}$

Agroecosystems refer to all the living communities of soil, plants, and animals that establish our farms, croplands, pastures, and rangelands ${ }^{1}$. We can say that our lives depend on agroecosystems as most of the crops and livestock we consume are produced by them. Although it is believed that agricultural ecosystems support far less biodiversity than other areas, at the largest scale, the agroecosystems interact with today's global economy, our society. ${ }^{15}$ It is irrefutable that agricultural practices influence wildlife in several ways, including, among others, habitat loss and disturbance, reduced natural water resources quality and quantity, and pesticide and herbicide toxicity. 
Besides, increase agricultural practices reduce agroecosystem biodiversity by decreasing the space allotted to hedgerows, copses, or wildlife corridors. In fact, it has been reported that noncrop areas in agricultural landscapes consecutively perform several ecological and agronomic functions (e.g. habitat, movement corridors and windbreak).The increasing interest in sustainable agriculture provides opportunities for increasing wildlife habitats in agroecosystems, taking on minor modifications of current practices. Some farmmanagement practices have already proven successful in making space for wildlife in agricultural ecosystems, such as (i) creating conservation-tillage systems, (ii) reducing herbicide application, (iii) leaving uncultivated strips within crop fields as habitat for weeding relatives of crop plants, (iv) windbreaks, (v) border plantings or live fences between plots or paddocks, or between farms, (vi) irrigation bunds, (vii) vegetative barriers to soil and water movement within crop fields, etc. ${ }^{16}$ Moreover, the damage of below-ground biodiversity which is a commonly overlooked issue is influenced by agricultural practices and changes in land use on the surface, ultimately affecting the well-being of farmers through reduced soil fertility, harvests, and incomes. ${ }^{15}$ The objectives of the present research were to explore the Noctuid fauna of Mashhad County and to estimate the species richness, species evenness and species diversity in agroecosystem.
These factors provide extremely useful measures of biodiversity and its fluctuations during time.

\section{Materials and methods}

Mashhad County (ca. 992-1184m above sea level) is the center of Khorasan-e-Razavi province of Iran. This province in North-East Iran is situated between Khorasan-e-Shomali (North Khorasan) and Khorasan-e-Jonoubi (South Khorasan), and surrounded by the Semnan and Yazd provinces in the west, and the countries Turkmenistan and Afghanistan in the east (Figure 1). This area of Iran is believed to be a transitional area in the Irano-Turanian subregion of the SaharoGobian biogeographic region of the Palaearctic realm. This specific situation of north-east Iran promises a rich fauna of insects especially for the family Noctuidae. The most prominent characteristics of the Khorasan flora and fauna is the presence of a large number of European, European-Mediterranean, and East Mediterranean species, and the combination of these elements with those of the Turanian region. ${ }^{17}$ Agroecosystems in Mashhad County are mainly including cereal plants, tomato, potato, onion and fruit trees like apple, pear, grape, apricot, cherry and peach. Sampling sites were chosen to form ensuring homogeneous cover of almost all agricultural plants in this area.

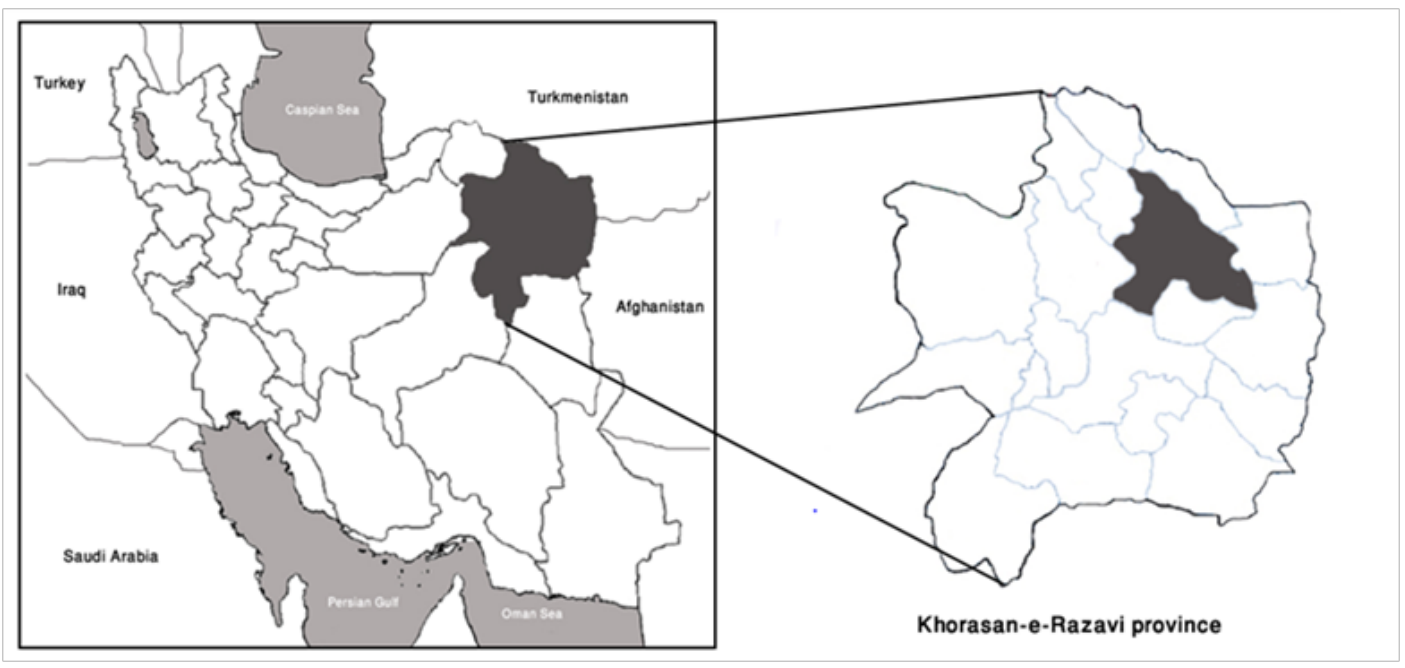

Figure I Map of Iran showing the situation of the Khorasan-e-Razavi province and the Mashhad county.

Data collecting was made randomly in the totally 31 sampling localities, for 3 days in each week, during April-August of 2014. Specimens were collected by using automated light traps (about $1 \mathrm{~m}$ in height, powered by 12 volt batteries and 8 watt UVB light tubes). All the collected adult moths were immediately processed, mounted and identified to species level and total population per month was also counted. Data obtained were analysed using the Species Diversity and Richness software (SDR), version 3.0. ${ }^{18}$ Shanon Diversity index (1), species richness (2), species evenness (3) and dominance (4) were calculated by Shannon-Diversity Index according to Magurran ${ }^{2}$ as below:

$$
\begin{aligned}
& \mathrm{H}=-\Sigma(\mathrm{pi} \times \ln (\mathrm{pi})) \\
& \mathrm{H}_{\text {max }}=\ln (\mathrm{N}) \\
& \mathrm{E}=\mathrm{H} / \mathrm{H}_{\text {max }}
\end{aligned}
$$

$$
\mathrm{D}=1-\mathrm{E}
$$

Where $\mathrm{N}$, is the total number of individual in the sample; pi, is the number of individual collected in each species; $\mathrm{H}$, is Diversity; $\mathrm{H}_{\max }$ is MaximumDiversity; E, is Evenness; and D, is Dominance.

All studied specimens are deposited in the collection of Plant Protection Department, Faculty of Agriculture, University of Birjand, Birjand, Iran.

\section{Results}

A total of 657 specimens of noctuid moths representing 38 different species were collected (Table 1). Collected species are belonging to eight subfamilies including Plusiinae, Metoponiinae, Acontiinae, Heliothinae, Bryophilinae, Xyleninae, Hadeninae and Noctuinae. Table 1 representing the collected species of each subfamily and 
the number of related specimens of each species collected in each month. Total collected specimens of each subfamily and the percent of relative abundance were shown in Table 2. These results indicated that more than $50 \%$ of the Noctuidae in the agroecosytems of Mashhad
County belonging to three subfamilies Plusiinae, Heliothinae and Noctuinae. Subfamilies Bryophilinae and Acontiinae have the least relative aboundance among the collected noctuids in this area, 1.07 and 2.44 , respectively.

Table I List of collected Noctuid species and their respective numbers in the five months

\begin{tabular}{|c|c|c|c|c|c|c|c|c|}
\hline Subfamily & species & Apr. & May & Jun. & Jul. & Aug. & Total & Avg. per month \\
\hline \multirow{3}{*}{ Plusiinae } & Autographa gamma & 5 & 9 & 14 & 10 & 8 & 46 & 9.2 \\
\hline & Trichoplusia ni & 8 & 8 & 10 & 9 & 8 & 43 & 8.6 \\
\hline & Chrysodeixis chalcites & - & I & 2 & 2 & I & 6 & 1.2 \\
\hline \multirow{2}{*}{ Metoponiinae } & Haemerosia albicomma & - & - & - & I & I & 2 & 0.4 \\
\hline & Tyta luctuosa & 4 & 5 & 6 & 7 & 4 & 26 & 5.2 \\
\hline \multirow{2}{*}{ Acontiinae } & Acontia lucida & - & I & 3 & 2 & 2 & 8 & 1.6 \\
\hline & A. trabealis & - & 1 & 2 & 3 & 2 & 8 & 1.6 \\
\hline \multirow[t]{3}{*}{ Heliothinae } & H. viriplaca & - & I & 2 & 2 & - & 5 & 1 \\
\hline & H. incarnata & I & $\mathrm{I}$ & 1 & - & 3 & 6 & 1.2 \\
\hline & Heliocoverpa armigera & 5 & 10 & 17 & 12 & 13 & 57 & 11.4 \\
\hline \multirow{2}{*}{ Bryophilinae } & Bryophila maeonis & - & - & I & - & - & I & 0.2 \\
\hline & B. raptricula & - & - & 5 & - & I & 6 & 1.2 \\
\hline \multirow{2}{*}{ Xyleninae } & Caradrinazerny & 1 & I & 2 & 2 & 4 & 10 & 2 \\
\hline & C. clavipalpis & $\mathrm{I}$ & 2 & 4 & I & I & 9 & 4.5 \\
\hline \multirow{4}{*}{ Hadeninae } & M. unipuncta & & 2 & 5 & 3 & 4 & 14 & 2.8 \\
\hline & M. I-album & 2 & 3 & 4 & 1 & $\mathrm{I}$ & II & 2.2 \\
\hline & Leucania loreyi & 4 & 4 & 6 & 6 & - & 15 & 3 \\
\hline & Lacanobia oleracea & 2 & 2 & 1 & - & - & 5 & I \\
\hline \multirow{10}{*}{ Noctuinae } & Euxoa aquilina & - & - & - & - & 2 & 2 & 0.4 \\
\hline & E. conspicua & - & - & 1 & - & - & 1 & 0.2 \\
\hline & E. sayvana & - & I & 1 & I & - & 3 & 0.6 \\
\hline & Agrotis segetum & 1 & 3 & 8 & 10 & 10 & 32 & 6.4 \\
\hline & A. ipsilon & 2 & 6 & 6 & 8 & 15 & 37 & 7.4 \\
\hline & A. crassa & - & 1 & 5 & 9 & 9 & 24 & 4.8 \\
\hline & A. exclamationis & - & - & 5 & - & I & 6 & 1.2 \\
\hline & Dichagyris flammatra & - & 1 & 2 & - & - & 3 & 0.6 \\
\hline & D. amoena & - & - & - & 2 & - & 2 & 0.4 \\
\hline & Xestia c-nigrum & - & - & 5 & I & - & 6 & 1.2 \\
\hline
\end{tabular}


Table 2 Total collected specimens of each subfamily and its relative abundance.

\begin{tabular}{llll}
\hline Subfamily & Specimens & $\begin{array}{l}\text { Relative } \\
\text { abundance (\%) }\end{array}$ & H value \\
\hline Plusiinae & 137 & 20.85 & 1.38 \\
Metoponiinae & 28 & 4.26 & 0.26 \\
Acontiinae & 16 & 2.44 & 0.69 \\
Heliothinae & 129 & 19.63 & 1.31 \\
Bryophilinae & 7 & 1.07 & 0.41 \\
Xyleninae & 113 & 17.2 & 0.83 \\
Hadeninae & 110 & 16.74 & 1.47 \\
Noctuinae & 117 & 17.81 & 1.76 \\
\hline
\end{tabular}

The diversity, species richness and evenness were calculated by Shannon index ${ }^{19}$ as shown in Table 3. This index considers both the number of species and the distribution of individuals among species. For a given number of species, the largest value $\mathrm{H}$ results when every individual belongs to different species and $\mathrm{E}$ are the relative measure of diversity. ${ }^{18}$ The overall insect biodiversity index of Shanon-Wiener was 3.11 in this study. Evenness was 0.85. A monthly change in population of the collected species of Noctuidae in the agroecosystems of Mashhad County is shown in Figure 2. As shown in this figure, the highest level of noctuids population, among the five collecting months, is recorded in the June and the lowest is in the April.

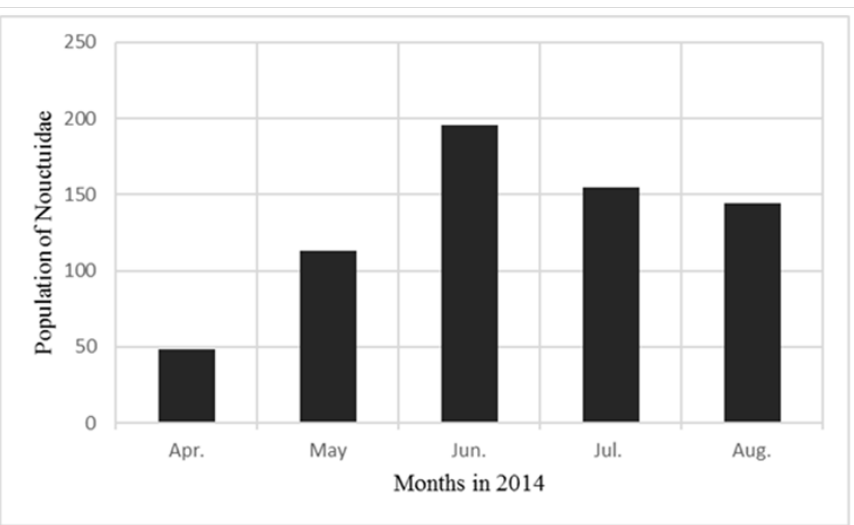

Figure 2 Monthly changes in the population of 38 collected species of Noctuidae in the study area.

Table 3 Biodiversity components of Noctuidae in agroecosystems of Mashhad County

\begin{tabular}{ll}
\hline Biodiversity components & Value in agroecosystems \\
\hline Species richness $(\mathrm{S})$ & 38 \\
Shannon Diversity Index $(\mathrm{H})$ & 3.11 \\
Max. Diversity $\left(\mathrm{H}_{\max }\right)$ & 3.64 \\
Evenness $(\mathrm{E})$ & 0.85 \\
Dominance $(\mathrm{D})$ & 0.15 \\
\hline
\end{tabular}

\section{Discussion}

Overall biodiversity indices showed relatively high biodiversity of Noctuidae in the study area, but existence of dominant speciesas, usually the diversity value over 3 refer to good level. ${ }^{20,21}$ Moreover, results showed that family Noctuidae was to some extent evenly distributed in the study area $(0.85)^{6,20}$ with the dominance of some species such as Spodoptera exigua (Hübner, 1808) and Heliocoverpaarmigera (Hübner, 1808) (0.15). According to the results, subfamily Noctuinae with 11 species and highest diversity index of $\mathrm{H}=1.76$, was the most diverse and abundant subfamily among the collected Noctuidae. Subfamilies Hadeninae and Plusiinae with diversity index, 1.47 and 1.38 are second and third diverse subfamilies among the collected noctuids, repectively. Most species richness in the Mashhad County is belonging to subfamilies Noctuinae and Hadeninae, 11 and 6, repectively. Metoponiinae, Acontiinae and Bryophilinae, each of them with only two collected species, had the least species richness and least diversity index compare to other collected subfamilies. These findings are in accordance with the previuos works which studied the fauna of family Noctuidae in this area $\mathrm{a}^{12,13,22}$ and even in other parts of Iran. ${ }^{9,13,22}$ The beet armyworm, S. exigua was dominant species, with relative abundance of $13.24 \%$ and the cotton bollworm, H. armigera was ranked as second dominant species, with relative abundance of $8.7 \%$. Both species are common polyphagous agricultural pests in the region which damage many economically important crops including corn, sugar beet, cotton, soybean, and tomato, annually. ${ }^{20,21}$ However, effective management practices for these pests are not still employed all over Mashhad County.

The fluctuation in monthly collected population of Noctuidae in Mashhad County (Figure 2) was attributed to the ecological conditions. The ecological conditions i.e. the rapid growth of plants and climatic factors ${ }^{23,24}$ caused the dispersal of insects within this area. Generally, based on the results, it seems that suitable ecological conditions and climatic factors such as optimum temperature in the region, should increase the insects' abundance gradually in late spring and early summer (Figure 1). Afterward, the noctuid population retains its high level, to some extent, in July and August. This study was a step toward the study different aspects of insect's biodiversity of Khorasan-e-Razavi province in north-east Iran. Lots of further researches are necessary in this regard and further collections are essential for getting a detailed periodic estimation of the Noctuidae diversity and development of standard monitoring procedures for assessing population fluctuation of different species of Noctuidae in this area.

\section{Conclusion}

Overall biodiversity indices showed relatively high biodiversity of Noctuidae in the study area, but existence of dominant species. Moreover, results showed that family Noctuidae was to some extent evenly distributed in the study area with the dominance of some species. The suitable ecological conditions and climatic factors such as optimum temperature in the region, increase the insects' abundance gradually in late spring and early summer. Afterward, the noctuid population retains its high level, to some extent, in July and August.

\section{Acknowledgments}

I wish to thank Dr. Mehdi Esfandiari for assistance with field collections. I also thank Dr. Javad Noei and Dr. Mohammad Saadati for assistance with preparation of the samples. This study was financially supported by a grant from the University of Birjand, Birjand, Iran.

\section{Conflict of interest}

Authors declare there is no conflict of interest in publishing the article. 


\section{References}

1. Solis MA. Snout moths: unraveling the taxonomic diversity of a speciose group in the Neotropics. In: Reaka-Kudla ML, Wilson DE, editors. Biodiversity II: Understanding and Protecting Our Biological Resources. Joseph Henry Press, Washington, DC; 1997. p. 231-242,551.

2. McNeely JA, Scherr S. Strategies to Enhance Wild Biodiversity in Agricultural Lands. Workshop on Agricultural Biodiversity, Nairobi, Kenya; 2001. p. 1-40,239.

3. Gullan PJ, Cranston PS. The Insects. An Outline of Entomology. 4th ed. Wiley-Blackwell Publishers; 2010. 565 p.

4. Rabieh MM, Esfandiari M, Seraj AA. A contribution to the fauna of subfamilies Metoponiinae, Bryophilinae and Xyleninae (Lepidoptera: Noctuidae) in NE Iran. Ir J Anim Biosyst. 2013;9(1):1-16.

5. Tuomisto H. A diversity of beta diversities: straightening up a concept gone awry. Part 1 . Defining beta diversity as a function of alpha and gamma diversity. Ecography. 2010;33:2-22.

6. Liu Z, Li D, Gong PY, et al. Life table studies of the cotton bollworm, Helicoverpa armigera (Hübner) (Lepidoptera: Noctuidae), on different host plants. Environ Entomol. 2004;33(6):1570-1576.

7. Greenberg SM, Sappington TW, Legaspi BC, et al. Feeding and life history of Spodoptera exigua (Lepidoptera: Noctuidae) on different host plants. Ann Entomol Soc Am. 2001;94(4):566-575.

8. Bienert T. Lepidopterological results of a trip to Iran in 1858 and 1859 [Lepidopterologische ergebnisse einer reise in Persien in den Jahren 1858 und 1859]. PhD dissertation, Univ. of Leipzig, Germany; 1870. $56 \mathrm{p}$.

9. Esfandiari M, Mossadegh MS, Shishehbor P. Noctuidae s.1. (Lepidoptera) from sugarcane fields of SW Iran. Fragm Faun. 2011;54(2):137-147.

10. Esfandiari M, Mossadegh MS, Shishehbor P, et al. Four noctuid (Lepidoptera, Noctuidae) taxa new for the fauna of Iran. Phegea. 2010;38(2):62-67.

11. Esfandiari M, Rabieh MM, Matov A, et al. A survey of Erebidae, Nolidae and Euteliidae (Lepidoptera) in Southern and Northeastern of Iran. Redia. 2015;98:77-92.

12. Rabieh MM, Seraj AA, Esfandiari M. Contribution to the noctuid fauna of NE Iran: Noctuinae, Hadeninae and Plusiinae (Lepidoptera), with additions to the Iranian fauna. Phegea, 2014;42(1):14-21.
13. Ravan B, Esfandiari M, Mossadegh MS, et al. Introduction on moths of Noctuinae (Lep.: Noctuidae) from southern areas of Zagros in Khuzestan and Fars provinces. Ir J Forest Range Prot Res. 2016;13(2):112-130.

14. Zahiri R, Fibiger M. The Plusiinae of Iran (Lepidoptera: Noctuidae). SHILAP Rev lep. 2008;36(143):301-339.

15. Alkorta I, Albizu I, Garbisu C. Biodiversity and agroecosystems. Biodivers Conserv. 2003;12:2521-2522.

16. Pogue MG. Biodiversity of Lepidoptera. In: Foottit RG, Adler PH, Editors. Insect Biodiversity: Science and Society. Blackwell Publishing, Oxford, UK; 2009. p. 325-355,623.

17. Fet V. Biogeographic Position of the Khorassan-Kopetdagh. In: Fet V, Atamuradov KI, Editors. Biogeography and Ecology of Turkmenistan. Kluwer Academic Publishers; 1994. p. 197-204,650.

18. Kikkawa J. Complexity, diversity and stability. In: Kikkawa J, Anderson DJ, editors. Community Ecology Pattern and Process. Blackwell Sci. Pub., Melbourne, Australia; 1996. p. 41-65,385.

19. Shannon CE. A mathematical theory of communication. Bell System Tech J. 1948;27:379-423.

20. Henderson PA, Seaby RMH. Species Diversity and Richness 3. Pisces Conservation Ltd., Pennington; 2002. p. 597.

21. Magurran AE. Measuring Biological Diversity. Blackwell Publishing, Maldeon, USA; 2004. p. 162-184.

22. Ebert G, Hacker HH. Contribution to the fauna of the Noctuidae of Iran: list of existing in the State Museum of Natural History Karlsruhe, taxonomic remarks and description of new taxa. Esperiana. 2002;9:237409.

23. Coley PD, Aide TM. Comparison of herbivory and plant defenses in temperate and tropical broad-leaved forests. In: Price PW, Lewinsohn TM, Editors. Plant-Animal Interactions: Evolutionary Ecology in Tropical and Temperate Regions. John Wiley \& Sons, Inc., New York; 1991. p. 25-49,639.

24. Kristensen NP, Scoble MJ, Karsholt O. Lepidoptera phylogeny and systematics: the state of inventorying moth and butterfly diversity. Zootaxa. 2007;1668:699-747. 